DS-06 .

\section{MAGNETIC PROPERTIES OF NANO-SCALE FePtCr-SiN THIN FILMS}

A. C. Sut. P. C. Kuw, S. C. Chen, and C. C. Cliang

Institure of Marerials Science and Eingineerritg, National Thiwan Lhiversily, Jaipei Ink, Jaiwan

\section{Introduction}

FePt alloy thin film is suitable for the magnetic recording media due to its high magnetocrystalline anisotropy $\left(\mathrm{Ku} \sim 7 \times 10^{7} \mathrm{erg} / \mathrm{cm}^{3}\right)$. However, it still has some disadvartages to be improved for high density recording media application, such as large grain size and high exchange coupling. High density recording media require ultrafine grain of about $10 \mathrm{~nm}$ or less. Previous investigations lave shown that the grain size of the FePt can be reduced by adding $\mathrm{Cr}$ into FePI film [1] or dispersing magnetic FePt grains inıo an amorphous non-magnetic $\mathrm{SiN}$ matrix [2]. Although granular $\mathrm{FePt}-\mathrm{Si}_{3} \mathrm{~N}_{4}$ thin film has good magnetic propertics for high density recording application, the mugnetic grain size of FePt-SiN film is still larger than $10 \mathrm{~nm}$. In this work we will add $\mathrm{Cr}$ into the FePt-SiN film to reduce its grain size and investigate the influences of $\mathrm{Cr}$ and $\mathrm{SiN}$ contents on the magnetic properties of the FePICr-SiN thin film.

\section{Experiment}

$\left[(\mathrm{FePt})_{301-x}-\left.\mathrm{Cr}_{\mathrm{x}}\right|_{\text {Lex } 1 \delta}-(\mathrm{SiN}) \delta\right.$ nanocomposite films (where $\mathrm{x}=0 \sim 25$ at. $\%$ and $\delta=0 \sim 30$ vol.\%) with thicknesses of $10 \mathrm{~nm}$ were produced on silicon wafer substrates at roon temperature by co-sputtering $\mathrm{Fe}_{50} \mathrm{Pt}_{50} . \mathrm{Cr}$ and $\mathrm{Si}_{3} \mathrm{~N}_{4}$ targets. The as-deposiled film was annealed in vacuum at various annealing temperature $T_{\text {an }}$ for 30 minutes then quenched in ice-water in order to get ordered $\mathrm{FePt} L \mathrm{~L}_{\text {al }}$ phase. Magnetic properties were measured by vibrating sample magnetometer (VSM) and superconducting quantum interference device (SQUD) with maximum applied fields of $13 \mathrm{kOe}$ and $50 \mathrm{kOe}$, respectively. Average grain size of the film was observed by transmission electron microscopy (TEM). The film thickness was measured by atomic force microscope (AFM).

\section{Rcsults and discussion}

Fig. I(a) and l(b) show the relationships arnong in-plane coercivity $\mathrm{Hc}_{\|}$, out-plane coercivity

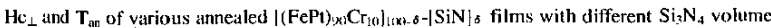

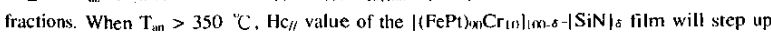
rapidly. The rapid decrease of $\mathrm{Hc}_{f /}$ for $\mathrm{T}_{\mathrm{an}}>650^{\circ} \mathrm{C}$ is due to the grain growth and the

reaction of $\mathrm{FePtCr}$ with the silicon substrate. $\mathrm{Hc}_{\perp}$ value also has the same tendency as that of $\mathrm{Hc}_{l /}$ as shown in Fig.l(b). The maximem $\mathrm{Hc}_{\perp}$ value is ahou $3.6 \mathrm{kOe}$, which is much smaller than that of $\mathrm{Hc}_{y}$. The magnetic anisotropy of these films are parallel to the film plane. From Fig.), we also sce that the increasc of $\mathrm{SiN}$ content in the film will increase the annealing temperature required for highest coercivity. This is due to the fact that the amorphous SiN phase is a poor heat-conductor, and postpones the initial temperature, which transforns the

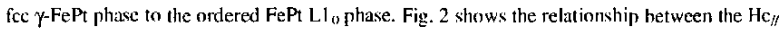

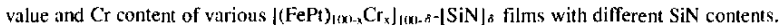
The annealing temperature is $600{ }^{\circ} \mathrm{C}$. The result shows the $\mathrm{Hc}_{/ /}$value decreased with increasing $\mathrm{Cr}$ and SiN contents.

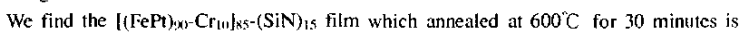
suitable for ligh-density magnetic recording application. Average grain size of the $\mathrm{FePICr}$ in this film is aboul $9 \mathrm{~nm}$. Its $\mathrm{Hc}_{\text {// }}$ is aboul $3.7 \mathrm{kDe}$, Ms is aboul $450 \mathrm{emu} / \mathrm{cm}^{3}$, and its in-plane squareness $\mathrm{S}_{/ 3}$ is about 0.75 .
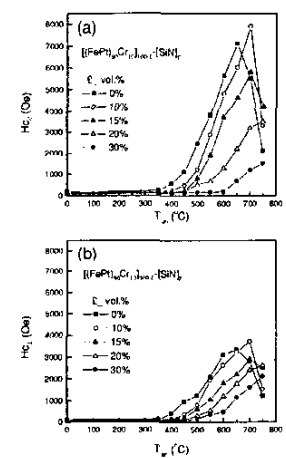

Fig. 1. The relationships among (a) $\mathrm{Hc}_{\text {/l, }}$ (b) $\mathrm{Hc}_{\perp}$, and $\mathrm{T}_{\mathrm{ar}}$ of the annealed

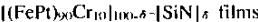

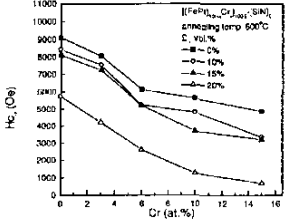

Fig. 2. Relationships between $\mathrm{Hc}_{f /}$ and the

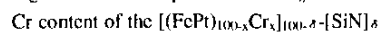
films.

\section{Reference}

[1] P. C. Kuo, Y. D. Yao, C. M. Kuo, and H. C. Wu, J. Appl. Phys., vol. $87,6146(2000)$ 12. Chith-Ming Kuo and P. C. Kuo, J. Appl. Phys., vol, 87, I (2000). 